\title{
Acquired Elastotic Hemangioma: Case Series and Comprehensive Literature Review
}

Philip R. Cohen ${ }^{1}$, Brian R. Hinds ${ }^{2}$

1. Dermatology, San Diego Family Dermatology, San Diego, USA 2. Dermatology, University of California San Diego, San Diego, USA

$\square$ Corresponding author: Philip R. Cohen, mitehead@gmail.com

Disclosures can be found in Additional Information at the end of the article

\section{Abstract}

\section{Background}

Acquired elastotic hemangioma is a benign vascular proliferation that typically presents as an asymptomatic red plaque on a sun-exposed site of an adult.

\section{Material and Methods}

The PubMed database was used to search the following words: acquired, angioma, arm, basal, carcinoma, cell, elastosis, elastotic, exposed, forearm, hemangioma, solar, sun, and vascular. The relevant papers and reference cited generated by the search were reviewed. The features from a case series of 11 patients with acquired elastotic hemangioma are presented. In addition, a comprehensive review of the characteristics of this unique hemangioma-not only in our 11 patients but also in the previously reported 34 individuals with this lesion-is provided.

\section{Results}

Acquired elastotic hemangioma, reported in 45 patients (24 women and 21 men), typically appeared as an asymptomatic solitary red plaque in sun-exposed areas-most commonly the forearm--of adults aged 50 years or older. The pathology shows a proliferation of vascular channels-surrounded and intertwined by intense solar elastosis--in the upper dermis, located parallel to the overlying epidermis, and separated from it by a zone of normal-appearing superficial papillary dermis. There was extensive solar elastosis surrounding and between the new blood vessels; some of the endothelial cells protrude (in a hob-nail pattern) into the vessel lumen. The clinical differential diagnosis includes basal cell carcinoma and the pathologic differential diagnosis includes other benign, malignant, and reactive vascular lesions.

Received 12/16/2017

Review began 12/20/2017

Review ended 12/27/2017

Published 12/28/2017

CC Copyright 2017

Cohen et al. This is an open access article distributed under the terms of the Creative Commons Attribution License CC-BY 3.0., which permits unrestricted use, distribution, and reproduction in any medium, provided the original author and source are credited.
Ultraviolet radiation may contribute to the pathogenesis of this hemangioma since it occurs on sun-exposed sites. There was no recurrence of the lesion following either excision or observation.

\section{Conclusions}

The possibility of acquired elastotic hemangioma should be considered by clinicians when they encounter an older individual with a new red plaque on a sun-exposed site that clinically appears to be a superficial basal cell carcinoma.

Categories: Dermatology, Pathology 


\section{Cureus}

Keywords: acquired, angioma, elastosis, elastotic, exposed, forearm, hemangioma, solar, sun, vascular

\section{Introduction}

Acquired elastotic hemangioma is a benign vascular proliferation that typically presents in older individuals on sun-exposed sites, such as the forearm. This lesion was initially described in six women in 2002 [1]; since then, it has only been reported in 28 additional patients [2-7]. A case series of 11 individuals with acquired elastotic hemangioma are described and the features of this lesion, including all 45 patients, are reviewed.

\section{Materials And Methods}

Eleven Caucasian patients (consisting of six men and five women) who were evaluated at the Department of Dermatology at the University of California San Diego from March 25, 2014 to October 11, 2017 were diagnosed with an acquired elastotic hemangioma. Clinical information was obtained from the pathology request form or the office notes or both. The following data were recorded for each patient: age, race, sex, lesion characteristics (such as size, appearance, clinical diagnosis, and duration), skin changes, lesions and/or cancers associated with sun exposure, other skin conditions, and systemic disorders.

\section{Results}

At the time of diagnosis, the men ranged in age from 57 to 81 years (median: 73 years) and the women ranged in age from 56 to 75 years (median: 70 years). Overall, the patients ranged from 56 to 81 years (median: 72 years) (Table 1 ).

\begin{tabular}{|c|c|c|c|c|c|c|c|c|c|}
\hline C & $\begin{array}{l}A \\
S\end{array}$ & Site & $\begin{array}{l}\text { Size } \\
\mathrm{mm}\end{array}$ & Appear & Clin Dx & $\begin{array}{l}\text { Dur } \\
\text { mon }\end{array}$ & $\begin{array}{l}\text { Sun } \\
\text { Expo }\end{array}$ & Skin Conditions & Systemic Disorders \\
\hline 1 & $\begin{array}{l}56 \\
W\end{array}$ & $\begin{array}{l}\text { Left upper } \\
\text { arm }\end{array}$ & $\begin{array}{l}4 x \\
4\end{array}$ & $\begin{array}{l}\text { Pink } \\
\text { papule }\end{array}$ & $\begin{array}{l}\text { AK, AMM, } \\
\text { Irr nevus }\end{array}$ & 1 & $\begin{array}{l}\text { MM, } \\
\text { Poik }\end{array}$ & $\begin{array}{l}\text { HSV, Nev Spilus, } \\
\text { SD, SK }\end{array}$ & Dys Dis, HypoT \\
\hline 2 & $\begin{array}{l}57 \\
M\end{array}$ & $\begin{array}{l}\text { Right } \\
\text { forearm }\end{array}$ & $\begin{array}{l}8 x \\
8\end{array}$ & $\begin{array}{l}\text { Ill-def pink } \\
\text { plaque }\end{array}$ & BCC & 6 & AK & $\begin{array}{l}\text { Angioma, } \\
\text { Nevi, SK, TP }\end{array}$ & Prostate Ca \\
\hline 3 & $\begin{array}{l}63 \\
M\end{array}$ & $\begin{array}{l}\text { Right } \\
\text { forearm }\end{array}$ & $\begin{array}{l}12 x \\
20\end{array}$ & $\begin{array}{l}\text { Red } \\
\text { dermal } \\
\text { plaque }\end{array}$ & AEH & 4 & $\begin{array}{l}\text { AK, } \\
\text { gBCC }\end{array}$ & $\begin{array}{l}\text { Nevi, Plantar } \\
\text { verruca }\end{array}$ & HTN \\
\hline 4 & $\begin{array}{l}65 \\
w\end{array}$ & Right calf & $\begin{array}{l}10 x \\
10\end{array}$ & $\begin{array}{l}\text { Red } \\
\text { dermal } \\
\text { plaque }\end{array}$ & $\begin{array}{l}\text { BCC, Bite, } \\
\text { CD30+, } \\
\text { SCCis }\end{array}$ & 4 & $\begin{array}{l}\mathrm{AK} \\
\mathrm{BCC}\end{array}$ & $\begin{array}{l}\text { HSV, Nevi, SD, } \\
\text { SK, TFFD }\end{array}$ & $\begin{array}{l}\text { CD30+, HLPD, } \\
\text { Osteo, RAD }\end{array}$ \\
\hline 5 & $\begin{array}{l}70 \\
w\end{array}$ & $\begin{array}{l}\text { Right } \\
\text { forearm }\end{array}$ & $\begin{array}{l}8 x \\
8\end{array}$ & Red plaque & NS & 3 & $\begin{array}{l}\text { Poik, } \\
\text { SCC }\end{array}$ & $\begin{array}{l}\text { DN, HSV Mi, Nevi } \\
\text { SK, TU, Ver Vulg }\end{array}$ & $\begin{array}{l}\text { Choleli, CIC, Colon } \\
\text { Adeno, DM, Gang, HTN, } \\
\text { Osteo }\end{array}$ \\
\hline 6 & $\begin{array}{l}72 \\
M\end{array}$ & $\begin{array}{l}\text { Right } \\
\text { upper arm }\end{array}$ & $\begin{array}{l}6 x \\
6\end{array}$ & $\begin{array}{l}\text { Red thin } \\
\text { papule }\end{array}$ & BLK, ISK & 4 & $\begin{array}{l}\text { AK, } \\
\text { Poik }\end{array}$ & $\begin{array}{l}\text { Angioma, Lentigo, } \\
\text { SK, TAD, Xerosis }\end{array}$ & $\begin{array}{l}\text { BPH, BSD, HLPD, HTN, } \\
\text { Pan C, RAD, Ret E, Thy } \\
\text { N }\end{array}$ \\
\hline 7 & 73 & Left & $15 x$ & Purple & FDE, KS, & 1 & None & SK & DM, HTN, HLPD, HypoT \\
\hline
\end{tabular}




\section{Cureus}

\begin{tabular}{|c|c|c|c|c|c|c|c|c|c|}
\hline & w & forearm & 15 & plaque & LP, LPPD & & & & \\
\hline 8 & $\begin{array}{l}73 \\
M\end{array}$ & $\begin{array}{l}\text { Left } \\
\text { forearm }\end{array}$ & $\begin{array}{l}4 x \\
4\end{array}$ & $\begin{array}{l}\text { Red, w } \\
\text { circ, fl top } \\
\text { papule }\end{array}$ & $\begin{array}{l}\text { Angioma, } \\
\text { PSK }\end{array}$ & 2 & $\begin{array}{l}\text { AK } \\
\text { BCC } \\
\text { MM } \\
\text { SCC }\end{array}$ & $\begin{array}{l}\text { Anal condyloma, } \\
\text { SK, Xerosis }\end{array}$ & $\begin{array}{l}\text { Colon Polyp, } \\
\text { DM, Nephrolith }\end{array}$ \\
\hline 9 & $\begin{array}{l}75 \\
W\end{array}$ & $\begin{array}{l}\text { Right } \\
\text { medial } \\
\text { distal leg }\end{array}$ & $\begin{array}{l}6 x \\
6\end{array}$ & $\begin{array}{l}\text { Kera red } \\
\text { plaque }\end{array}$ & BCC & 6 & $\begin{array}{l}\text { AK, } \\
B C C, \\
\text { SCCis }\end{array}$ & $\begin{array}{l}\text { Angioma, DMC, } \\
\text { SK, TU, Var veins }\end{array}$ & Osteo \\
\hline 10 & $\begin{array}{l}78 \\
M\end{array}$ & $\begin{array}{l}\text { Left post- } \\
\text { auricular }\end{array}$ & $\begin{array}{l}10 x \\
5\end{array}$ & NS & BCC & NS & BCC & NS & NS \\
\hline 11 & $\begin{array}{l}81 \\
M\end{array}$ & $\begin{array}{l}\text { Right } \\
\text { upper arm }\end{array}$ & $\begin{array}{l}>4 x \\
4\end{array}$ & $\begin{array}{l}\text { Red-purple } \\
\text { patch }\end{array}$ & $\begin{array}{l}\text { Solar } \\
\text { purpura, } \\
\text { vasculitis }\end{array}$ & 2 & AK & $\begin{array}{l}\text { Angioma, } \\
\text { Dermatitis, FP, } \\
\text { Nevi, Sub Hem }\end{array}$ & GERD, Osteo, Pulm Nod \\
\hline
\end{tabular}

\section{TABLE 1: Clinical Features of 11 Patients with Acquired Elastotic Hemangioma}

Abbreviations: Adeno: adenoma; AEH: acquired elastotic hemangioma; AK: actinic keratosis; AMM: amelanotic melanoma; Appear: appearance of skin lesion (color and morphology); BCC: basal cell carcinoma; BLK: benign lichenoid keratosis; BPH: benign prostatic hypertrophy; BSD: bone (and disc) spinal disease; Choleli: cholelithiasis; CD30+: CD30+ lymphoproliferative disorder; CIC: chronic interstitial cystitis; Clin Dx: clinical diagnosis submitted on pathology requisition; Def, defined; DM: diabetes mellitus; DMC: digital mucous cyst; DN: dysplastic nevus; Dys Dis: dysthymic disease; Dur: duration of lesion prior to biopsy; FDE: fixed drug eruption; FI Top: flat topped; FP: fibrous papule; Gang: ganglion; gBCC: giant basal cell carcinoma; GERD: gatroesophageal reflux disease; HLPD: hyperlipidemia; HSV: herpes simplex virus infection; HTN: hypertension; HypoT: hypothyroidism; Irr: irritated; ISK: inflamed seborrheic keratosis; Kera: keratotic; KS: Kaposi sarcoma; LP: lichen planus; LPPD: lichenoid pigmented purpuric dermatitis; M: man; Mi: milia; MM: malignant melanoma; mon: months, mm: millimeters; Nephrolith: nephrolithiasis; Nev: nevus; NS: not stated; Osteo: osteoporosis; Pan C: pancreatic cyst; Poik: poikiloderma; PSK: purpuric seborrheic keratosis; Pulm Nod: pulmonary nodule; RAD: reactive airway disease; Ret E: Retrograde ejaculation (secondary to finasteride treatment for benign prostatic hypertrophy); SCC: squamous cell carcinoma; SCCis: squamous cell carcinoma in situ; SD: seborrheic dermatitis; SK: seborrheic keratosis; Sub Hem: subungual hematoma; Sun Expo: sun exposure-related condition, lesion, or skin cancer; TAD: transient acantholytic dermatosis; TFFD: terra firma forme dermatosis; Thy N: thyroid nodule; TP: tinea pedis; TU: tinea ungium; Var: varicose; Ver Vulg: verruca vulgaris; W: woman, W Circ: well circumscribed

The asymptomatic hemangiomas were located on either the right (seven patients) or left (four patients) side of the body. The most common sites were the upper extremity (eight patients), distal lower extremity (two patients), and the postauricular area (one patient). The forearm was the most common site (five patients) followed by the upper arm (three patients).

The lesions ranged in size from $4 \times 4 \mathrm{~mm}$ to $12 \times 20 \mathrm{~mm}$; the median size was $8 \times 8 \mathrm{~mm}$. They were red (six patients), pink (two patients), purple (one patient), or red-purple (one patient); the color was not provided for one of the individuals. The most common morphology was a plaque (six patients) - two of these patients' lesions were described as dermal plaques. Other morphologies included papules (three patients) and a patch (one patient); the morphology was not stated for one patient.

Clinical diagnoses were provided on the pathology requisition, the office visit note, or both for 10 of the patients; a total of 21 diagnoses (of 18 different conditions) were submitted. The number of diagnoses in the differential ranged from one to four (median: two diagnoses). Basal cell carcinoma (four patients) and seborrheic keratosis (two patients with either benign lichenoid keratosis and irritated seborrheic keratosis or purpuric seborrheic keratosis) were the most common diagnoses. Other alternative diagnoses, based on the appearance of the lesion 
(each in one patient), included actinic keratosis, amelanotic melanoma, angioma, bite, CD30+ lymphoproliferative disorder, fixed drug eruption, irritated nevus, Kaposi sarcoma, lichen planus, lichenoid pigmented purpuric dermatosis, solar purpura, squamous cell carcinoma in situ, and vasculitis. One clinician correctly suggested the diagnosis of acquired elastotic hemangioma.

All of the acquired elastotic hemangiomas had similar pathologic features. Within the upper reticular dermis, there was an increased number of bland-appearing, thin-walled vessels arranged parallel to the overlying epidermis. Solar elastosis, usually severe, was present around the vascular channels and in the intervening dermal stroma. In addition, each only in one woman, either a perivascular lymphocytic infiltrate (Table 1, Case 1) or extravasated erythrocytes and focal hemosiderin (Table 1, Case 9) were also present.

The acquired elastotic hemangioma appeared between one to six months (median: four months) prior to evaluation; the lesion duration was not described in one patient. Ten of the patients had a history of skin changes, lesions, and/or cancer suggestive of moderate to severe sun exposure, including poikiloderma (three patients), actinic keratoses (seven patients), basal cell carcinoma (five patients, one of whom had a giant tumor, a $10 \times 8 \times 2.5 \mathrm{~cm}$ mass on his upper back), squamous cell carcinoma (three patients, one of whom had an in situ tumor), and malignant melanoma (two patients). The number of sun-related conditions per patient ranged from one to four (mean: two conditions); more commonly, there were either two conditions (five patients) or one condition (three patients) and only one patient had either three or four conditions.

The patients with acquired elastotic hemangioma also had other skin conditions and systemic disorders; whether these conditions and disorders are etiologically related to the development of acquired elastotic hemangioma remains to be determined. These included benign skin lesions (such as angioma, cysts, nevi, and seborrheic keratoses), dermatophyte infections (such as onychomycosis and tinea pedis), dermatoses (such as dermatitis, seborrheic dermatitis, terra firma forme dermatosis, transient acantholytic dermatosis, and xerosis), varicose veins, and viral infections (such as condyloma, herpes simplex virus, and verruca vulgaris). They also included benign lesions and tumors (such as benign prostatic hypertrophy, colon adenoma, ganglioma, pancreactic cyst, pulmonary nodule, and thyroid nodule), bone diseases (such as osteoporosis and spine disease), chronic interstitial cystitis, drug reactions (such as finasterideassociated retrograde ejaculation), endocrine disorders (such as diabetes mellitus and hypothyroidism), gastroesophageal reflux disease, hyperlipidemia, hypertension, neoplastic conditions (such as CD30+ lymphoproliferative disorder and prostate cancer), osteoporosis, reactive airway disease, and stone disease (cholelithiasis and nephrolithiasis).

\section{Discussion}

\section{History}

Luis Requena (from Madrid, Spain) along with Heinz Kutzner and Thomas Mentzel (two colleagues from Friedrichshafen, Germany) provided the original description of a new variant of cutaneous hemangioma in the September 2002 issue of the Journal of the American Academy of Dermatology (Table 2) [1-7]. They described the clinical, pathological, and immunohistochemical features of a solitary vascular lesion in six women between the ages of 59 to 66 years (median age: 64 years) that was located on sun-damaged skin of the extensor forearm (five patients) or lateral neck (one patient); the endothelial cells of all of the lesions' capillaries stained strongly positive for CD31 and CD34 (markers for blood vessel differentiation). In order to emphasize the clinicopathologic characteristics of this hemangioma, they chose the descriptive name of acquired elastotic hemangioma [1]. 


\section{Cureus}

\begin{tabular}{|c|c|c|}
\hline $\begin{array}{l}\text { Author } \\
\text { Reference }\end{array}$ & $\begin{array}{l}\text { Pub } \\
\text { year }\end{array}$ & Contribution \\
\hline $\begin{array}{l}\text { Requena, } \\
\text { et al. [1] }\end{array}$ & 2002 & $\begin{array}{l}\text { They designated } \mathrm{AEH} \text { as the descriptive name for a hemangioma variant of a new vascular } \\
\text { proliferation. They provided a clinical, histopathologic, and immunohistochemical study of six women } \\
\text { with a solitary vascular lesion on the sun-damaged skin of the forearm (five patients) or lateral neck } \\
\text { (one patient). }\end{array}$ \\
\hline $\begin{array}{l}\text { Martorell- } \\
\text { Calatayud, } \\
\text { et al. [2] }\end{array}$ & 2010 & $\begin{array}{l}\text { They presented the largest series of } 14 \text { AEH patients (eight men and six women); eight of the } \\
\text { patients' lesions were on the forearm. They proposed a lymphatic origin for AEH since the } \\
\text { endothelial cells from nine of } 10 \text { lesions studied expressed a marker of lymphatic endothelial cell } \\
\text { differentiation: D2-40 (podoplanin). }\end{array}$ \\
\hline $\begin{array}{l}\text { Tong and } \\
\text { Beer [3] }\end{array}$ & 2010 & $\begin{array}{l}\text { They presented } 10 \text { patients (six men and four women) with AEH. They suggested that AEH was } \\
\text { derived from blood-instead of lymphatic-vascular lineage since only one of } 10 \text { lesions showed } \\
\text { positive staining for D2-40. }\end{array}$ \\
\hline $\begin{array}{l}\text { Tillman, et } \\
\text { al. [4] }\end{array}$ & 2015 & $\begin{array}{l}\text { They authored a case report of a woman with seven new AEH her bilateral upper extremities over } \\
\text { five years. The lesions appeared after initiating progesterone therapy; new lesions stopped } \\
\text { developing and some lesions showed mild regression after stopping the progesterone. }\end{array}$ \\
\hline $\begin{array}{l}\text { Hicks and } \\
\text { Katz [5] }\end{array}$ & 2016 & $\begin{array}{l}\text { They reported the first description of the dermatoscopic features of } \mathrm{AEH} \text { in a case report of a man } \\
\text { with a lesion on the dorsum of his hand. }\end{array}$ \\
\hline $\begin{array}{l}\text { Mendieta- } \\
\text { Eckert, et } \\
\text { al. [6] }\end{array}$ & 2017 & $\begin{array}{l}\text { They described the successful dual-wavelength vascular laser treatment of AEH on the cleavage } \\
\text { area of a woman's chest. The case report discussed that each of the three treatment sessions (every } \\
\text { six weeks) consisted of using a pulsed dye }(585 \mathrm{~nm}) \text { laser followed by a Nd:YAG }(1,064 \mathrm{~nm}) \text { laser. } \\
\text { Examination after five months of treatment--two weeks after her third treatment--showed that a } \\
\text { complete response, without recurrence, had been achieved. }\end{array}$ \\
\hline $\begin{array}{l}\text { Ben } \\
\text { Rejeb, et } \\
\text { al. [7] }\end{array}$ & 2017 & $\begin{array}{l}\text { Their case report described a woman with } \mathrm{AEH} \text { on her right cheek that was clinically interpreted as a } \\
\text { basal cell carcinoma and treated with an excisional biopsy. }\end{array}$ \\
\hline $\begin{array}{l}\text { Cohen and } \\
\text { Hinds } \\
\text { (current } \\
\text { report) }\end{array}$ & 2017 & $\begin{array}{l}\text { They presented a case series of } 11 \text { patients (six men and five women) with AEH on sun-exposed } \\
\text { skin of the upper extremity (eight patients), lower extremity (two patients), or postauricular area (one } \\
\text { patient) and provided a comprehensive review of this benign vascular lesion. Their series increased } \\
\text { the number of reported AEH patients by } 32 \%(11 / 34) \text {; the number of individual described also } \\
\text { comprises } 24 \% \text { (11/45) of the published AEH patients. They emphasized that ultraviolet radiation } \\
\text { may have an etiologic role in the pathogenesis of AEH and show that } 91 \% \text { (10 of 11) of their patients } \\
\text { had a history of skin changes, lesions, and/or cancer suggestive of moderate to severe sun } \\
\text { exposure. }\end{array}$ \\
\hline
\end{tabular}

\section{TABLE 2: Significance of Acquired Elastotic Hemangioma Publications}

Abbreviations: AEH: acquired elastotic hemangioma; Nd:YAG: neodymium-doped yttrium aluminum garnet; nm: nanometers, Pub: publication

It was not until eight years later that Martorell-Calatayud, et al. reported-in the April 2010 issue of the Journal of Cutaneous Pathology-the features of acquired elastotic hemangioma in a series of 14 patients: eight men and six women, ranging in age from 51 to 82 years (median 
age: 65 years). The solitary lesions were located on the forearm (eight patients), lower lip (two patients), hand (one patient), nostril (one patient), and shoulder (one patient); the site was not specified in one patient. They proposed that this acquired vascular proliferation was of lymphatic origin based on the expression of D2-40 (podoplanin, a specific marker of lymphatic differentiation) in nine of the 10 lesions they studied [2].

That same year-in the December 2010 issue of the Journal of Cutaneous Pathology-Tong and Beer reported 10 additional patients (six men and four women) with a solitary acquired elastotic hemangioma on either the arm (nine patients) or upper chest (one patient). The patients were in good health, had no history of immunosuppression, and ranged in age from 50 to 79 years (median age: 59.7 years). The authors demonstrated that the lymphatic endothelial marker D2-40 was positive in only one of the 10 lesions, which suggested that most of the acquired elastotic hemangiomas were of a blood vessel-and not lymphatic vascular-lineage [3].

Half a decade would pass before the next report of an acquired elastotic hemangioma. Tillman, et al. had a resident poster presentation at the fall meeting of the American Osteopathic College of Dermatology that was held in Orlando, Florida from October 15-18, 2015. They presented a 57-year-old woman who developed multiple lesions on both of her upper extremities after initiating progesterone therapy. The report was subsequently published in the December 2015 issue of Practical Dermatology [4].

In the following year, a case report by Hicks and Katz, highlighting the dermatoscopic features of an acquired elastotic hemangioma on the dorsal hand of a man in his 60's, was published in the April 2016 issue of Dermatology Practical and Conceptual [5]. Subsequently, two additional patients with this vascular lesion have been reported in 2017 [6-7]. In March 2017, the successful vascular laser treatment of an acquired elastotic hemangioma located on the cleavage of a 65-year-old woman by Mendieta-Eckert, et al. was published in Dermatology Surgery [6]. Also, in the October 2017 issue of Our Dermatology Online Journal, Ben Rejeb, et al. described a 64-year-old woman with an acquired elastotic hemangioma on her right cheek [7].

We currently present a series of 11 additional patients (six men and five women) with a solitary acquired elastotic hemangioma. They range in age from 56 to 81 years (median age: 72 years). The vascular lesions were located on their upper extremity (eight patients), lower extremity (two patients), and postauricular (one patient).

\section{Epidemiology}

Acquired elastotic hemangiomas have been described in 45 patients: 24 women and 21 men [17], as well as the current report (Tables 3-4); hence, the lesion occurs slightly more often in women than men with the women to men ratio of eight to seven. Their age-when the diagnosis was established--ranged from 50 to 82 years (median: 63 years). At the time of diagnosis, the women ranged in age from 50 to 76 years (median: 61 years) and the men ranged in age from 53 to 82 years (median: 68 years).

\begin{tabular}{|lllll|}
\hline C & Age $(\mathbf{y r})$ & Location & Clinical diagnosis & Ref \\
\hline 1 & 50 & R forearm & Actinic keratosis, squamous cell carcinoma & [3] C7 \\
2 & 51 & L forearm & BCC & [2] C4 \\
3 & 53 & Not stated & Not stated & [2] C10 \\
\hline
\end{tabular}




\section{Cureus}

\begin{tabular}{|c|c|c|c|c|}
\hline 4 & 55 & $L$ forearm & BCC (superficial) & [2] C5 \\
\hline 5 & 55 & $L$ forearm & $\mathrm{BCC}$ & [2] C11 \\
\hline 6 & 55 & R upper arm & Not stated & [3] C2 \\
\hline 7 & 56 & L upper arm & AMM, angioma, inflamed nevus & CR1 \\
\hline 8 & 57 & $\mathrm{R}$ forearm & BCC & [2] C3 \\
\hline 9 & 57 & $R$ and $L$ forearm and $a^{1}{ }^{1}$ & Kaposi sarcoma, PAT, THH & [4] \\
\hline 10 & 59 & $\mathrm{R}$ forearm & SCCis & [1] C3 \\
\hline 11 & 60 & $L$ forearm & BCC & [1] C5 \\
\hline 12 & 60 & L clavicle & $\mathrm{BCC}$ & [3] C3 \\
\hline 13 & 61 & L biceps & Vascular lesion & [3] C8 \\
\hline 14 & 63 & $L$ forearm & Lupoid lesion & [1] C1 \\
\hline 15 & 64 & R neck (lateral) & BCC & [1] C6 \\
\hline 16 & 64 & R cheek & BCC & [7] \\
\hline 17 & 65 & Chest (central) $^{2}$ & Hemangioma, inflammatory lesion, $\mathrm{LH}$ & [6] \\
\hline 18 & 65 & R calf & BCC, bite, CD30+ LD, SCCis & CR4 \\
\hline 19 & 66 & $L$ forearm & Erythema, hemangioma & [1] C2 \\
\hline 20 & 70 & R upper arm & Vascular lesion & [2] C12 \\
\hline 21 & 70 & R forearm & Not stated & CR5 \\
\hline 22 & 73 & $L$ forearm & FDE, Kaposi sarcoma, LP, LPPD & CR7 \\
\hline 23 & 75 & R distal leg (medial) & BCC & CR9 \\
\hline 24 & 76 & for & $\mathrm{BC}$ & [1] C4 \\
\hline
\end{tabular}

\section{TABLE 3: Clinical Characteristics of Women with Acquired Elastotic Hemangioma}

Abbreviations: AMM: amelanotic malignant melanoma; BCC: basal cell carcinoma; C: case; CD30+ LD: CD 30+ Iymphoproliferative disorder; CR: current report; FDE: fixed drug eruption; L: left; LH: lymphoid hyperplasia; LP: lichen planus; LPPD: lichenoid pigmented purpuric dermatosis; PAT: purpura annularis telangiectoides; R: right; Ref: reference; SCCis: squamous cell carcinoma in situ; THH: targetoid hemosiderotic hemangioma

${ }^{1}$ The woman had a total of seven erythematous, well-defined, non-tender, slightly elevated, non-blanching plaques on her arms bilaterally; the largest was on the right lower forearm.

${ }^{2}$ The single lesion was localized in her cleavage. 


\section{Cureus}

\begin{tabular}{|c|c|c|c|c|}
\hline C & Age (yrs) & Location & Clinical diagnosis & Ref \\
\hline 1 & 53 & $\mathrm{~L}$ forearm & BCC, squamous cell carcinoma in situ & [3] C4 \\
\hline 2 & 54 & $\mathrm{R}$ forearm & BCC & [3] C1 \\
\hline 3 & 57 & R forearm & $\mathrm{BCC}$ & CR2 \\
\hline 4 & 59 & $L$ forearm & BCC, lichenoid keratosis, nevus & [3] C10 \\
\hline 5 & 60 's & L hand (dorsal) & Granuloma annulare & [5] \\
\hline 6 & 61 & R upper arm & Not stated & [3] C6 \\
\hline 7 & 63 & Lower lip & BCC & [2] C6 \\
\hline 8 & 63 & R forearm & Acquired elastotic hemangioma & CR3 \\
\hline 9 & 65 & $\mathrm{R}$ hand (dorsum) & BCC & [2] C14 \\
\hline 10 & 65 & $L$ forearm & Not stated & [3] C5 \\
\hline 11 & 68 & R nostril & BCC & [2] C9 \\
\hline 12 & 69 & $L$ forearm & BCC & [2] C1 \\
\hline 13 & 70 & $\mathrm{R}$ forearm & BCC & [2] C13 \\
\hline 14 & 71 & R forearm & Ecchymosis & [2] C2 \\
\hline 15 & 72 & R upper arm & BLK, irritated seborrheic keratosis & CR6 \\
\hline 16 & 73 & $L$ forearm & Angioma, purpuric seborrheic keratosis & CR8 \\
\hline 17 & 76 & L lip & Vascular lesion & [2] C8 \\
\hline 18 & 78 & L postauricular & BCC & CR10 \\
\hline 19 & 79 & L shoulder & BCC (with dilated blood vessels) & [3] C9 \\
\hline 20 & 81 & R upper arm & Solar purpura, vasculitis & CR11 \\
\hline 21 & 82 & L shoulder & BCC & [2] C7 \\
\hline
\end{tabular}

\section{TABLE 4: Clinical Characteristics of Men with Acquired Elastotic Hemangioma}

Abbreviations: BCC: basal cell carcinoma; BLK: benign lichenoid keratosis; C: case; CR: current report; L: left; R: right; Ref: reference

The lesion is usually asymptomatic. However, at least two patients noted the lesion to be painful: one of the women described by Requena, et al. [1] and a 57-year-old woman right forearm acquired elastotic hemangioma (Table 3, Case 8) [2]. None of the patients had a history of trauma, previous procedure, or radiotherapy at the site of their vascular lesion.

\section{Clinical presentation}




\section{Cureus}

Acquired elastotic hemangiomas typically present as solitary pink to red to purple, ill-defined yet well-demarcated, slowly growing patches or plaques (Figure 1). However, one woman had a total of seven acquired elastotic hemangiomas on her upper extremities [4]. The individual lesions range in size from $4 \times 4 \mathrm{~mm}$ (Table 1, Case 1) to $5 \times 5 \mathrm{~cm}$ [1].
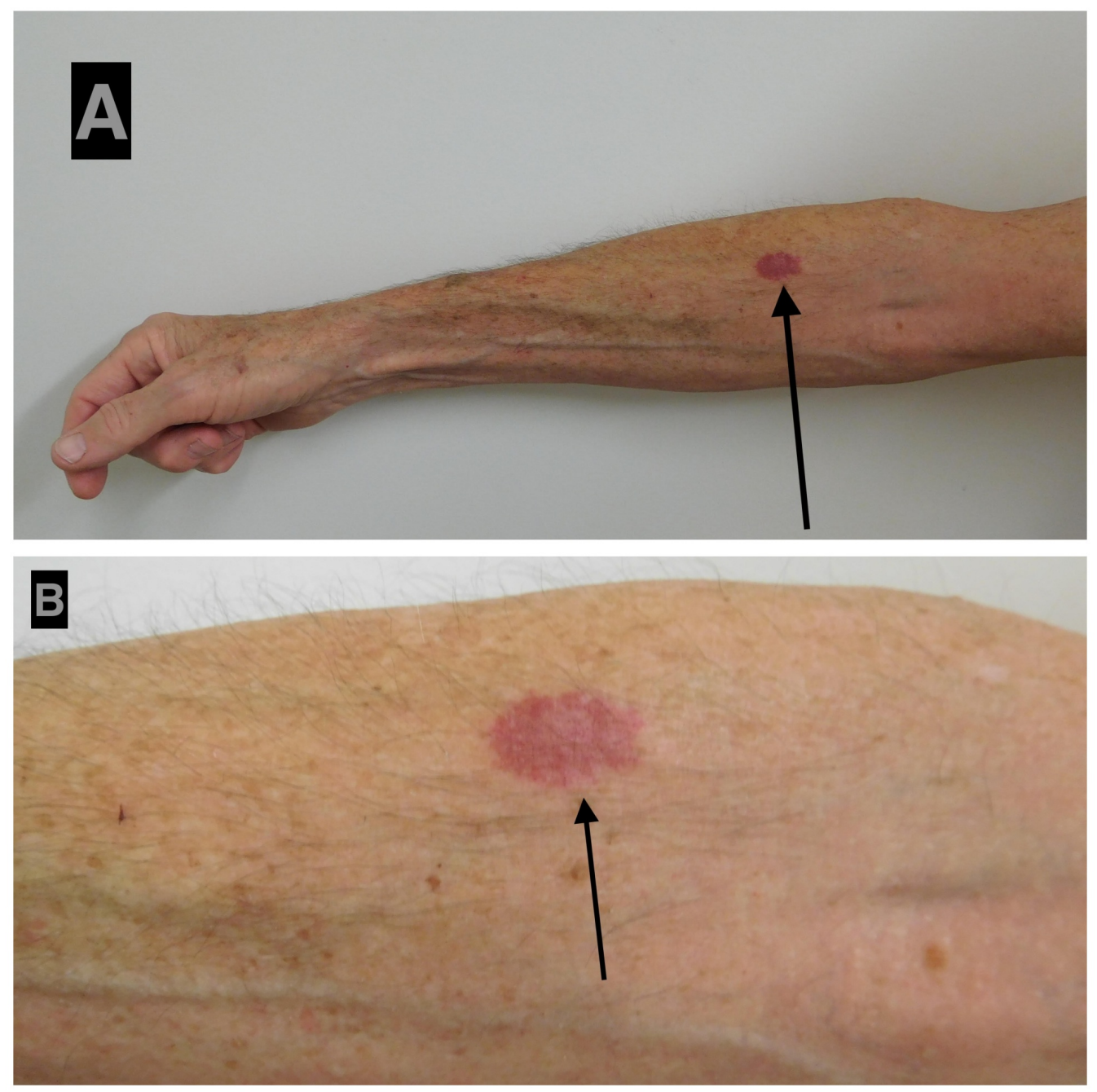

\section{FIGURE 1: Acquired elastotic hemangioma: right forearm of a 63-year-old man}

Distant (A) and closer (B) views of an asymptomatic $12 \times 20 \mathrm{~mm}$ red dermal plaque on his right forearm of four months duration. The man had a history of hypertension, actinic keratoses (that had been treated with liquid nitrogen cryotherapy), and a giant $(10 \times 8 \times 2.5 \mathrm{~cm})$ basal cell carcinoma on his upper central back (that had been successfully treated with a combination of vismodegib and nivolumab). According to the patient, the lesion began as a 'pimple' that he picked; the affected area enlarged and remained as a red lesion beneath his skin. The clinical differential diagnosis of the right forearm lesion, acquired elastotic hemagioma, was confirmed by the pathology features observed on the biopsy of the lesion: variable-sized compact vascular channels lined by cytologically bland endothelial cells in the superficial dermis; elastosis was present around the vascular channels and in the intervening dermal stroma.

Acquired elastotic hemangiomas are diascopy-negative. Diascopy refers to using a clear material, such as a glass microscope slide, to press against a skin lesion to assess for blanchability; some vascular lesions, such as telangiectasias, acquire a blanched appearance after the lesion has been depressed since the blood dissipates intravascularly [8]. Blanchability 


\section{Cureus}

of acquired elastotic hemangiomas was evaluated in 21 patients; none of the lesions blanched under diascope pressure $[1-2,7]$.

Acquired elastotic hemangioma frequently occurs on sun-exposed areas. They occurred on the left side (22 patients: 12 women and 10 men) and on the right side ( 21 patients: 11 women and 10 men) of the body; one woman, with multiple hemangiomas, had lesions on both sides of her body [4]. Lesions also occurred on the lower lip (one man) and the central chest cleavage area (one woman).

The most common location of an acquired elastotic hemangioma was an upper extremity (32 patients, 71\%) (Table 5) [1-7] and the current report. The forearm was more frequently involved (23 patients) than the upper arm (seven patients), the dorsal hand (two patients), and the biceps (one patient); one woman had lesions on both her forearm and upper arm (Table 3, Case 9) [4]. The lesions also occurred on the head and neck (six patients), the back and chest (four patients), and the lower extremity (two patients) (Figures 2-3). The lesion location was not provided for a 53-year-old woman (Table 1, Case 3) [2]. 


\section{Cureus}

\section{Site}

Upper extremity

Forearm $^{1}$

Upper arm ${ }^{1}$

Hand

Biceps

Head and neck

Lip

Cheek

Neck

Nostril

Postauricular

Back and chest

Shoulder

Clavicle

Cleavage

Total

Lower extremity (calf or distal leg)

Total

Not stated

Total

TOTAL
1

1

2

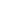

\section{2}

2

1

1

0

1

2

4 


\section{Cureus}
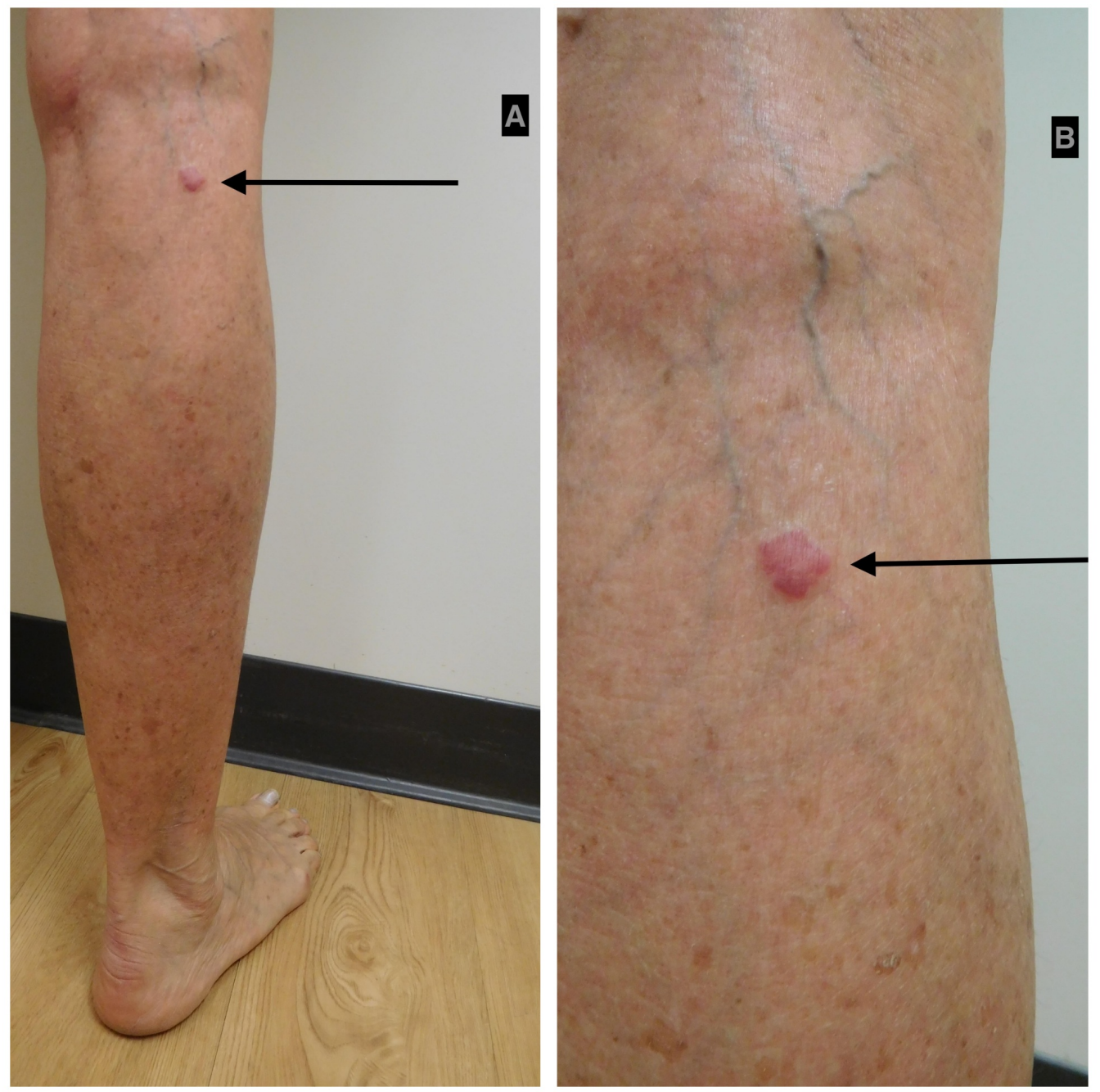

\section{FIGURE 2: Acquired elastotic hemangioma: right calf of a 65- year-old woman}

Distant $(A)$ and closer $(B)$ views of an asymptomatic $10 \times 10 \mathrm{~mm}$ red dermal plaque on the superior aspect of the right calf of four months duration. The woman had a history of a CD30-positive lymphoproliferative disease involving her left leg that was diagnosed 17 years earlier and successfully treated with radiotherapy nine years ago without recurrence. She also had a history of hyperlipidemia, osteoporosis, and reactive airway disease. In addition, she previously had several basal cell carcinomas that had been excised and actinic keratoses that had been treated with liquid nitrogen cryotherapy. She was unaware of the right calf lesion; however, it had not been present at her total body skin check four months earlier. The clinical differential diagnosis of the right calf lesion included arthropod bite reaction, basal cell carcinoma, CD30-positive lymphoproliferative disorder, and squamous cell carcinoma in situ. The diagnosis of acquired elastotic hemangioma was established by the changed note on the lesion biopsy: multiple small capillaries situated in the superficial dermis amidst elastotic material. 


\section{Cureus}
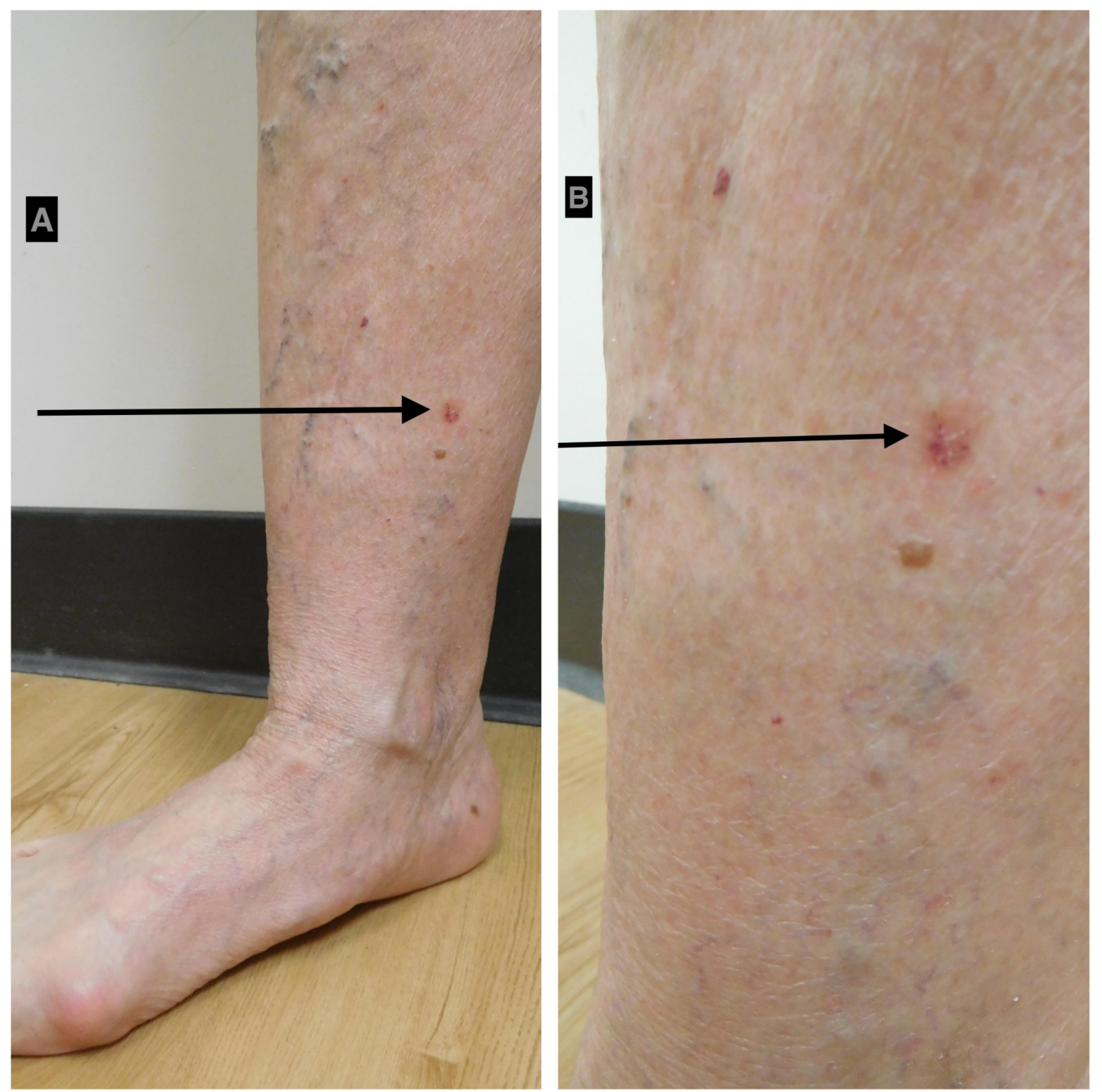

\section{FIGURE 3: Acquired elastotic hemangioma: right medial distal leg of a 75-year-old woman}

Distant $(\mathrm{A})$ and closer $(\mathrm{B})$ views of an asymptomatic $6 \times 6 \mathrm{~mm}$ keratotic red plaque on the right medial distal leg of six months duration. The woman had a history osteoporosis. She also had a history of basal cell carcinoma and squamous cell carcinoma that were excised and actinic keratoses that had been treated with liquid nitrogen cryotherapy. The clinical differential diagnosis of the right medial distal leg lesion was basal cell carcinoma. An excision shave biopsy was performed; the diagnosis of acquired elastotic hemangioma was established by the pathology findings: an increase in vascular lobules within the dermis with extensive solar elastosis; focal hemosiderin and extravasated red blood cells were also present.

The location of the acquired elastotic hemangiomas was similar in women and in men. In women, acquired elastotic hemangiomas most commonly appeared on the forearm (13 patients), the upper arm (four patients), and the leg (two patients); as previously mentioned, one of the women had lesions on both her forearm and upper arm (Table 3, Case 9) [4]. Other sites, each in one woman, included the biceps, the cheek, the chest (cleavage area), the clavicle, and the neck. In men, the lesions most frequently appeared on the forearm (10 patients), the upper arm (three patients), and--in two men each-on the hand (dorsum), the lip, and the shoulder. Other sites, each in one man, included the nostril and the postauricular area.

\section{Dermoscopy}


The dermatoscopic features of acquired elastotic hemangioma were described by Hicks and Katz [5]. They evaluated an $8 \times 6 \mathrm{~mm}$ violaceous plaque-like lesion (with a slightly raised thin border and a mildly rough surface without scale) on the left lateral dorsal hand of a man in his 60's. The new lesion was asymptomatic and had only been noticed two weeks prior.

Non-polarizing dermatoscopy of the lesion-at standard magnification--showed a homogenous, non-pigmented violaceous plaque, without obvious vasculature; there were no keratin features or ulceration. However, polarized dermatoscopy shows prominent and widespread shiny white structures distributed evenly throughout the lesion. The investigators suggested that the shiny white areas that they observed were a specific polarization artifact that may have been caused by the horizontal band-like proliferation of capillaries with intervening collagen bundles in the superficial dermis [5].

\section{Pathology}

Biopsy and excision specimens of acquired elastotic hemangiomas from the patients in this clinical series and the previously reported individuals showed similar pathologic changes (this series report; [1-7]); indeed, there were some papers that demonstrated the microscopic features of acquired elastotic hemangioma but did not discuss any of the clinical aspects from the photomicrographs they included [9-11]. There was a band-like proliferation of capillary blood vessels, arranged parallel to the epidermis, that was present in the superficial dermis. The endothelial cells lining the vessels were bland; they did not have cellular or nuclear atypia and there were few to no mitoses. However, in some areas, the endothelial cells showed a 'hobnail pattern' by protruding into the lumen of the vessels (Figure 4) [1-3].

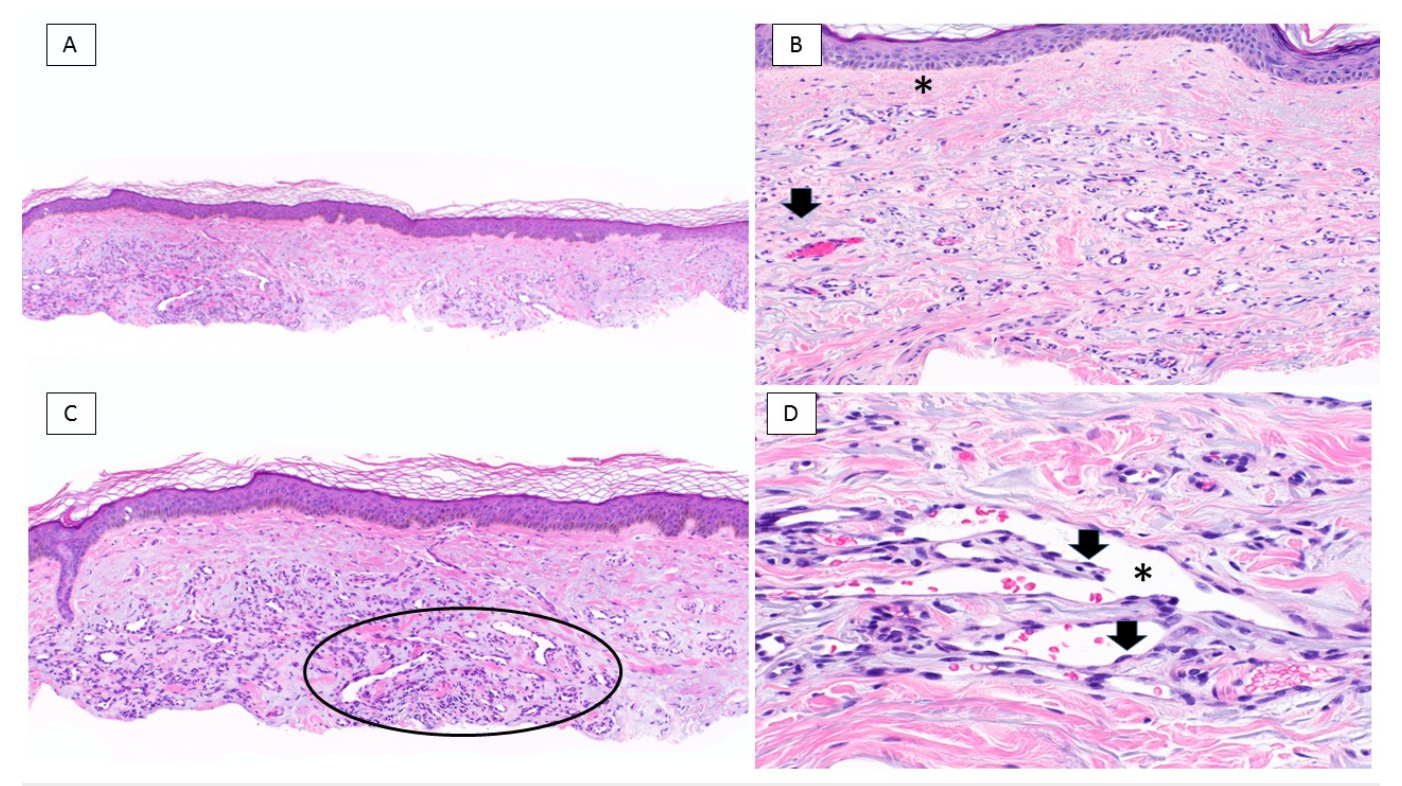

\section{FIGURE 4: Acquired elastotic hemangioma: pathology features}

A low magnification view $(A)$ of a thin shave biopsy shows sun-damaged skin of the forearm; there is a well-delineated, horizontally oriented proliferation of vascular channels. Higher magnification views $(B, C$, and $D)$ highlight specific pathologic changes. There is a grenz zone showing a narrow band of the papillary dermis uninvolved by underlying pathology (asterisk); also, blue elastotic fibers (arrow) are intertwined with compactly arranged, thin-walled vascular channels (B). Some of the lesion's blood vessels (circle) display jagged, slit-like spaces (C). Focal protrusion of endothelial cells (arrows) toward the center of the lumen of the vascular space (asterisk) is noted; the constituent endothelial cells lack nuclear atypia (D) (Hematoxylin and eosin: A, x 4; B, x 20; C, x 10; D, $x$ 40). 


\section{Cureus}

Another characteristic feature of an acquired elastotic hemangioma was the prominent solar elastosis of the collagen bundles surrounding and intermingled with the proliferation of capillaries. In addition, the overlying epidermis was either normal or atrophic and was separated from the vascular proliferation by a grenz zone - a narrow band of the papillary dermis uninvolved by underlying pathology [12]. The presence of either a perivascular lymphocytic infiltrate (Table 1, Case 1) or extravasated erythrocytes and focal hemosiderin (Table 1, Case 9) were considered to be coincidental findings in two of the women from our case series.

Immunoperoxidase studies show uniformly showed positive staining of the endothelial cells with CD31 or CD34 or both, which are markers that support a capillary vascular lineage for acquired elastotic hemangioma [1-3, 7]. Although Martorell-Calatayud, et al. demonstrated positive D2-40 (podoplanin, a specific marker of lymphatic differentiation) in nine of the 10 lesions they studied, which was suggestive of a lymphatic origin for this vascular proliferation, a follow-up study by Tong and Beer only demonstrated positive D2-40 staining vessels in only one of the 10 cases they evaluated and CD34-positive staining vessels in all of these cases. The latter investigators concluded that most acquired elastotic hemangiomas were of blood vascular-and not lymphatic vascular-lineage [3].

In some of the acquired elastotic hemangioma lesions, the pericytes surrounding the vascular channels stained positive for alpha-smooth muscle actin [1-2, 7]. Requena, et al. observed positive staining in all of the six lesions they evaluated [1]. Similarly, Ben Rejeb, et al. noted positive staining in the lesion from their patient (Table 3, Case 16) [7]. However, MartorellCalatayud, et al. only demonstrated positive staining in one of the 10 lesions they studied [2].

Proliferating markers (anti-mitotic proteins antibody (MPM-2) and/or Ki-67) were evaluated by two groups of researchers. Only a few nuclei of the endothelial cells of the acquired elastotic hemangioma blood vessels stained positive with MPM-2 and Ki-67 in the six lesions reported by Requena, et al. [1]. None of the 10 lesions studied by Martorell-Calatayud, et al. showed positive staining for Ki-67 [2]. The endothelial cells of the vessels were also negative for human herpes virus-8 (HHV-8) staining in one patient's lesions (Table 3, Case 16) [7].

\section{Differential diagnosis}

The clinical differential diagnosis of acquired elastotic hemangioma includes neoplastic and benign tumors, other vascular lesions, dermatoses, and other conditions (Table 6) (current series; [1-7]). Sixty diagnoses were suggested by the clinicians who biopsied 40 of the 45 patients; there were five patients (three women and two men) for whom a clinical diagnosis was not stated. The number of diagnoses submitted ranged from one (27 patients) to four (two patients); the median number of submitted diagnoses was one. Two diagnoses were considered in seven patients and three diagnoses were entertained in four patients.

\begin{tabular}{|c|c|c|}
\hline Diagnosis $^{1}$ & Women & Men \\
\hline \multicolumn{3}{|l|}{ Neoplastic tumors or pre-neoplastic lesions } \\
\hline Basal cell carcinoma & 11 & 12 \\
\hline Squamous cell carcinoma (invasive or in situ) & 3 & 1 \\
\hline Kaposi sarcoma & 2 & 0 \\
\hline Actinic keratosis & 1 & 0 \\
\hline
\end{tabular}




\section{Cureus}

CD30+ lymphoproliferative disorder

Malignant melanoma (amelanotic)

Total

Vascular lesions (benign)

Angioma (hemangioma)

Vascular lesion (not otherwise specified)

Ecchymosis and purpura (solar)

Acquired elastotic hemangioma

Erythema

Targetoid hemosiderotic hemangioma

Vasculitis

Total

Dermatoses and other conditions

Bite

Fixed drug eruption

Granuloma annulare

Inflammatory lesion (not otherwise specified)

Lichen planus

Lichenoid pigmented purpuric dermatosis

Lymphoid hyperplasia

Lupoid lesion

Purpura annularis telangiectoides

Total

Benign tumors (non-vascular)

\section{Keratoses $^{2}$}

Nevus (irritated and not otherwise specified)

Total

TOTAL
0

1

1

34

\section{(1)}

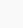

2




\section{Cureus}

${ }^{2}$ Keratoses include one of each of the following lesions: benign lichenoid keratosis, irritated seborrheic keratosis, lichenoid keratosis (not otherwise specified), and purpuric seborrheic keratosis.

Basal cell carcinoma was the most common diagnosis (23 patients); this represented 39\% (23 of 59 submitted diagnoses) of the diagnoses suggested on the pathology requisition. The next most frequent diagnoses-each listed four times-were squamous cell carcinoma (invasive or in situ), angioma (hemangioma), and benign keratosis (in three men). A vascular lesion (not otherwise specified) in three patients, and either Kaposi sarcoma or ecchymosis and purpura (solar) each in two patients were the other diagnoses suggested more than once.

The pathologic differential diagnosis of acquired elastotic hemangioma includes benign (such as acquired tufted hemangioma, angioma, and targetoid hemosiderotic hemangioma) and malignant (such as angiosarcoma, Dabska tumor, Kaposi sarcoma, and retiform hemangioendothelioma) vascular lesions (Table 7) [1-2, 4, 7, 9, 11, 13-15]. The endothelial cells that line the vascular channels in acquired elastotic hemangioma can be plump and protrude into the vessel lumina in a hobnail pattern; therefore, other vascular proliferations with a hobnail pattern (such as angiosarcoma, Dabska tumor, retiform hemangioendothelioma, and targetoid hemosiderotic hemangioma) need to be considered and excluded. Also, other vascular lesions with similar pathologic features (such as Dabska tumor and tufted hemangioma) can be excluded since they typically appear in childhood--in contrast to acquired elastotic hemangioma that presents in older individuals. 


\section{Cureus}

\section{Condition}

Acquired tufted hemangioma (angioblastoma of Nakagawa)

Acroangiodermatitis of Mali (pseudo-Kaposi sarcoma)

Angioma (cherry or senile)

Angiosarcoma (low-grade, well-differentiated)

Cutaneous collagenous vasculopathy

Dabska tumor (endovascular papillary angioendothelioma)

Kaposi sarcoma (early patch stage)

Reactive epithelial, vascular and eccrine sweat duct changes ${ }^{1}$

Retiform hemangioendothelioma

Stewart-Bluefarb syndrome (pseudo-Kaposi sarcoma)

Targetoid hemosiderotic hemangioma (hobnail hemangioma)

\section{References}

$[1-2,4,7]$

$[1-2,7,9]$

$[1-2,7,11]$

$[2,11]$

[13-14]

[2]

$[1-2,4,7,9]$

[2]

[1]

$[1,4]$

\section{TABLE 7: Pathologic Differential Diagnosis of Acquired Elastotic Hemangioma}

${ }^{1}$ Acquired elastotic hemangioma-like changes and eccrine sweat duct squamous metaplasia in lichen simplex chronicus and prurigo nodularis-like lesions of the knees and elbow seem to represent non-neoplastic epithelial, vascular, and eccrine sweat duct reactive changes-likely associated with chronic pressure or repeated mechanical stimulation-which have a marked predilection for the knee and elbow.

In addition, the pathologic differential diagnosis of acquired elastotic hemangioma includes cutaneous collagenous vasculopathy. Clinically, cutaneous collagenous vasculopathy usually presents as asymptomatic blanchable telangiectasias on the trunk and extremities; it is morphologically similar in appearance to generalized essential telangiectasias or pigmented purpuric dermatosis. Microscopically, similar to acquired elastotic hemangioma, there are dilated blood vessels in the superficial dermis. However, in contrast to acquired elastotic hemangioma, the walls of the vessels in cutaneous collagenous vasculopathy are thickened with hyaline material that is not only periodic acid-Schiff stain-positive but also shows Type IV collagen immunoreactivity and severe solar elastosis around and between the vessels is not a characteristic feature [13-14].

Also, reactive vascular lesions-such as pseudo-Kaposi sarcoma (acroangiodermatitis of Mali and Stewart-Bluefarb syndrome)-are in the pathologic differential diagnosis. Recently, Kacerovska, et al. [15] described a reactive lesion of not only vascular elements but also epithelial and eccrine sweat ducts that occurs on the knee and the elbow-sites associated with chronic pressure or repeated mechanical stimulation. The vascular changes in these lesions are similar to those observed in acquired elastotic hemangioma; however, there is also squamous metaplasia of the eccrine ducts and epithelial changes consistent with lichen simplex chronicus and prurigo nodularis.

\section{Pathogenesis}


There is evidence that long-term sun exposure contributes to the development of acquired elastotic hemangioma [1-3, 7]. First, there was severe elastosis in the dermis of the lesions. Second, the lesions occurred on locations that were exposed to the sun-most commonly the upper extremity and, specifically, the forearm. Third, as demonstrated by 91\% (10 of 11) of the patients in the current case series, many of the affected individuals had a history of skin changes, lesions, and/or cancer suggestive of moderate to severe sun exposure, including poikiloderma, actinic keratoses, basal cell carcinoma, squamous cell carcinoma, and malignant melanoma; two of the patients reported by Tong and Beer had multiple prior basal cell carcinomas [3].

Tillman, et al. raised the possibility of hormonal influence in the pathogenesis of acquired elastotic hemangioma. Their patient, a 57-year-old woman, developed seven of these lesions on both of her upper extremities during the five-year period after she began progesterone therapy. Indeed, after stopping progesterone, she not only stopped developing new acquired elastotic hemangiomas but also experienced that some of the lesions showed mild regression $[4]$.

The patients in the current case series had several other skin conditions and systemic disorders (Table 1). Similarly, the woman with seven acquired elastotic hemangiomas also had a history of rosacea and hypertension [4]. However, an association between the pathogenesis of acquired elastotic hemangioma and any of other the skin conditions or systemic disorders that these individuals have remains to be established.

\section{Treatment}

Acquired elastotic hemangioma is a benign vascular lesion. However, prior to establishing the prognosis for this lesion, most of the tumors were excised (25 patients) [1-3, 5, 7]. However, in more recent reports (including the patients in this case series), the acquired elastotic hemangioma were biopsied to establish the diagnosis and the residual lesion was observed (19 patients) [3, 4]; one woman, with seven lesions who was monitored clinically, developed no new tumors and had mild regression of her current hemangiomas after discontinuing progesterone [4]. The remaining patient's acquired elastotic hemangioma, which was located on the cleavage area of her chest, was successfully removed after three treatment sessions (spaced at six-week intervals) using a dual-wavelength laser system (Table 3, Case 17); she received a maximum of 9 Joules per square centimeter (spot 7 millimeters, pulse duration of 0.5 milliseconds) with a pulsed dye laser ( 585 nanometers) and 145 Joules per square centimeter (spot 5 millimeters, pulse duration 15 milliseconds) with a neodymium-doped yttrium aluminum garnet (Nd:YAG) (1,064 nanometers) [6].

\section{Prognosis}

All of the patients in our case series only had biopsies of their lesions without additional treatment or lesion-specific follow-up. However, follow-up was provided for 18 patients with acquired elastotic hemangioma in the literature. Whether treated with excision (10 patients) [1, $3,5]$, laser (one patient) [6], or observation (seven patients) [3], none of the patients had a recurrence of their lesions.

\section{Conclusions}

Acquired elastotic hemangioma, a benign-usually asymptomatic--vascular proliferation, was originally described in 2002. Including the patients in this case series, it has been reported in 45 patients: 24 women and 21 men. The lesion typically appeared in sun-exposed sites of adults; the youngest individual was 50 years old and the oldest patient was 82 years old; the median onset age is 63 years. The hemangioma presented as a solitary pink to red to purple 
patch or plaque; however, one woman developed seven lesions after beginning progesterone therapy. The most common location is the forearm (23 patients); other frequent sites included the upper arm (seven patients), the head and neck (six patients), and the back and chest (four patients); one woman had lesions on both her forearm and upper arm. All of the lesions had similar pathology features: a proliferation of vascular channels in the upper dermis, located parallel to the overlying epidermis, and separated from it by a grenz zone in the superficial papillary dermis. There was extensive solar elastosis surrounding and between the new blood vessels, some of which showed a hobnail-like protrusion of the endothelial cells into the vessel lumen. Basal cell carcinoma was the most common clinical differential diagnosis (23 patients); the pathologic differential diagnosis included not only benign and malignant vascular tumors but also reactive vascular lesions. The predominance of lesions in areas that have been exposed to sun suggests that ultraviolet radiation has a role in the pathogenesis of acquired elastotic hemangioma. Earlier investigators did not observe recurrence of the lesion following either excision or observation. One woman's lesion was successfully treated with dual wavelength laser therapy and another woman had mild regression of her hemangiomas (and no new lesions) after discontinuing progesterone.

In summary, we suspect that this vascular lesion occurs more frequently than the small number of publications and reported patients would indicate. Also, we recommend that clinicians entertain the possibility of this acquired hemangioma when they encounter an older individual with a new red plaque on a sun-exposed site that clinically appears to be a superficial basal cell carcinoma. The distinctive pathology observed on a biopsy of the lesion-severe solar elastosis around and within a proliferation of vessels in the upper dermis that is distributed parallel to the overlying epidermis--will establish the diagnosis.

\section{Additional Information \\ Disclosures}

Human subjects: Consent was obtained by all participants in this study. Animal subjects: All authors have confirmed that this study did not involve animal subjects or tissue. Conflicts of interest: In compliance with the ICMJE uniform disclosure form, all authors declare the following: Payment/services info: All authors have declared that no financial support was received from any organization for the submitted work. Financial relationships: All authors have declared that they have no financial relationships at present or within the previous three years with any organizations that might have an interest in the submitted work. Other relationships: All authors have declared that there are no other relationships or activities that could appear to have influenced the submitted work.

\section{References}

1. Requena L, Kutzner H, Mentzel T: Acquired elastotic hemangioma: a clinicopathologic variant of hemangioma. J Am Acad Dermatol. 2002, 47:371-76. 10.1067/mjd.2002.122737

2. Martorell-Calatayud A, Balmer N, Sanmartin O, et al.: Definition of the features of acquired elastotic hemangioma reporting the clinical and histopathological characteristics of 14 patients. J Cutan Pathol. 2010, 37:460-64. 10.1111/j.1600-0560.2009.01361.x

3. Tong PL, Beer TW: Acquired elastotic hemangioma: ten cases with immunohistochemistry refuting a lymphatic origin in most lesions. J Cutan Pathol. 2010, 37:1259-60. 10.1111/j.16000560.2010.01610.x

4. Tillman N, Plumb SJ, Cleaver D, et al.: Acquired elastotic hemangioma. Pract Dermatol. 2015, 12(12):26,29.

5. Hicks T, Katz I: First description of the dermatoscopic features of acquired elastotic hemangioma-a case report. Dermatol Pract Concept. 2016, 6:35-37. 10.5826/dpc.0604a08

6. Mendieta-Eckert M, Díaz-Ramón JL, Gardeazabal-García J: Response of an acquired elastotic hemangioma to vascular laser. Dermatol Surg. 2017, March:Epub ahead of print. 10.1097/DSS.0000000000001105 
7. Ben Rejeb S, Chelly I, Zehani A, et al.: Acquired elastotic hemangioma: a diagnosis to keep in mind. Our Dermatol Online. 2017, 6:443-45. 10.7241/ourd.20174.125

8. Cohen PR: Red dot basal cell carcinoma: report of cases and review of this unique presentation of basal cell carcinoma. Cureus. 2017, 9:e1110. 10.7759/cureus.1110

9. Goh SG, Callonje E: Cutaneous vascular tumours: an update. Histopathology. 2008, 52:66173. 10.1111/j.1365-2559.2007.02924.x

10. Sangüeza OP OP: Update on vascular neoplasms. Dermatol Clin. 2012, 30:657-65. 10.1016/j.det.2012.06.013

11. Acquired Elastotic Haemangioma Pathology. (2013). Accessed: December 6, 2017 : http://www.dermnetnz.org/topics/acquired-elastotic-haemangioma-pathology.

12. Abbas O, Mahalingam M: The grenz zone. Am J Dermatopathol. 2013, 35:83-91. 10.1097/DAD.0b013e31824feb4e

13. Castiñeiras-Mato I, Rodríguez-Lojo R, Fernández-Díaz ML, Bal-Nieves F: Cutaneous collagenous vasculopathy: a case report and review of the literature (Article in English, Spanish). Actas Dermosifiliogr. 2016, 107:444-47. 10.1016/j.ad.2015.11.006

14. Rambhia KD, Hadawale SD, Khopkar US: Cutaneous collagenous vasculopathy: a rare case report. Indian Dermatol Online J. 2016, 7:40-42. 10.4103/2229-5178.174327

15. Kacerovska D, Portelli F, Michal M, Kazakov DV: Acquired elastotic hemangioma-like changes and eccrine sweat duct squamous metaplasia in lichen simplex chronicus/prurigo nodularislike lesions of the knee and elbow. J Cutan Pathol. 2017, April:Epub ahead of print.

10.1111/cup. 12945 